\section{Delayed Facial Palsy after Microvascular Decompression for Trigeminal Neuralgia}

\section{Sir,}

A 72-year male patient was admitted to the hospital with trigeminal neuralgia of right side for 6 years and underwent microvascular decompression (MVD) of the trigeminal nerve and developed delayed facial palsy (DFP) postoperatively (Figure 1). The patient gave a history of facial palsy on the right side 10 years back, which was recovered completely. The pain disappeared completely after surgery. But after 12 days, the patient developed a right-sided facial palsy. He was treated with methyl-prednisolone, nimodipine and acyclovir for 7 days; clearly improved shortly after treatment initiation and completely recovered from palsy four weeks later.

Compared with hemifacial spasm (HFS), the incidence of (DFP) after MVD for trigeminal neuralgia (TN) is very low, and the reason is unclear. There is a lack of literature on DFP after MVD for trigeminal neuralgia. On reviewing the literature of DFP after MVD for HFS, we think that the possible causes may be the reactivation of virus and a microcirculation disturbance due to vasospasm.

Hengstman et al. ${ }^{1}$ and Furukawa et al. ${ }^{2}$ have described DFP after MVD for HFS was due to the reactivation of varicella zoster virus and herpes simplex virus. Lovely et al. ${ }^{3}$ thought that the virus, lying dormant in the geniculate ganglion, is triggered by manipulation of the nerve or nervus intermedius during operation and may be a factor for DFP after MVD for HFS. Based on our experience, it is common to find the patients with TN or HFS treated by MVD to develop herpes simplex lesions on their oral mucosa or lips, which also confirms that the surgical manipulation of the nerve may cause viral reactivation.
In this case, the patient had a history of facial palsy. Unfortunately, we did not test for specific serum antibodies for varicella zoster or herpes simplex virus.

Zhao $\mathrm{H}$ et al. ${ }^{4}$ thought the vasospasm of small vessels, around facial nerve, might be one of the factors for DFP after MVD for HFS. Scheller et al. ${ }^{5}$ have reported that a microcirculation disturbance due to vasospasm caused DFP following acoustic neuroma resection.

The vasospasm after MVD for HFS may cause by intraoperative traction and the blood infiltrating into the subarachnoid space. It results in reduced facial nerve blood supply, which affects nerve function. In this case, DFP occurred 12 days after surgery. It is consistent with the peak period of vasospasm, caused by the subarachnoid blood, which is about 1 week.

With respect to the above two possible mechanisms, the authors believe that it may be useful in prevention of DFP, if following measures are taken: during operation, the facial nerve should be protected carefully, and only the responsible blood vessels should be manipulated to reduce bleeding and vessels traction; after operation, vasoactive therapy with nimodipine should be instituted as early as possible, and preventive use of antiviral drugs may be useful for patients with a history of facial paralysis. Methylprednisolone, nimodipine and acyclovir are effective treatments. Further studies and more cases are needed to clarify the etiology, prevention, and therapy of DFP after MVD for TN.

\section{CONFLICT OF INTEREST:}

Authors declared no conflict of interest.

\section{AUTHORS' CONTRIBUTION:}

WT, XM, JZ: Contributed to the design of the work; drafting the work and revising it critically for important intellectual content; approved the final version to be published.

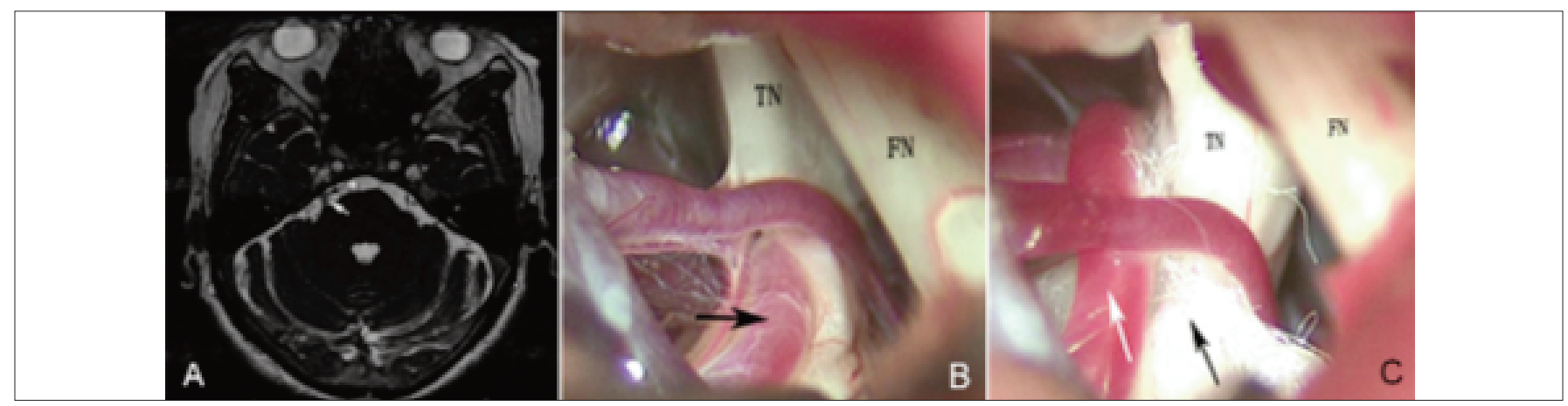

Figure 1: (A) MRI showing the compression of the right trigeminal nerve (white arrow: crossing artery; black arrow: trigeminal nerve). (B) Compression of the right trigeminal nerve (black arrow: crossing artery). TN: trigeminal nerve; FN: facial nerve. (C) Decompression of the right trigeminal nerve (white arrow: crossing artery; black arrow:Teflon patch). TN: trigeminal nerve; FN: facial nerve. 


\section{REFERENCES}

1. Hengstman GJ, Gons RA, Menovsky T, Lunelc FV, Van CJ, de VJ. Delayed cranial neuropathy after neurosurgery caused by herpes simplex virus reactivation: Report of three cases. Surg Neurol 2005, 64:67-9.

2. Furukawa K, sakoh M, Kumon Y, Teraoka M, Ohta S, Ohue S, et al. Delayed facial palsy after microvascular decompression for hemifacial spasm due to reactivation of varicella-zoster virus. No Shinkeigeka 2003; 31:899-902.

3. Lovely TJ, Getch CC, Jannetta PJ. Delayed facial weakness after microvascular decompression of cranial nerve VII. Surg Neurol 1998; 50:449-52.

4. Zhao $\mathrm{H}$, Tang YD, Wang $\mathrm{XH}$, Ying TT, Zhu J, Yuan $\mathrm{Y}$, et al. Delayed facial palsy after microvascular decompression for hemifacial spasm. J Craniofac Surg 2016; 27:781-3.
5. Scheller C, Staruss C, Fahlbusch R, RomstÖk J. Delayed facial nerve paresis following acoustic neuroma resection and postoperative vasoactive treatment. Zentralbl Neurochir 2003; 65:103-7.

Wei Tian, Xin Meng and Jidian Zou

Department of Neurosurgery, Weihai Central Hospital, China Correspondence to: Dr. Jidian Zou, West No. 3, Mishan Dong Road, Wendeng District, Weihai City, Shandong Province, China

E-mail: zoujidian@126.com

Received: April 18, 2019; Revised: July 09, 2019; Accepted: July 20, 2019

$\cdots \ldots$ 